\section{Case of cardiac arrest due to carbon dioxide poisoning following an explosion of a carbon dioxide tank}

\author{
Young Bin Ok', Jin Yong Kim², Kwang Je Baek', Kyeong Ryong Lee', \\ Dae Young Hong ${ }^{1}$, Sang 0 Park' , Jong Won Kim', Sin Young Kim ${ }^{1}$ \\ 'Department of Emergency Medicine, Konkuk University Medical Center, Konkuk University School of \\ Medicine, Seoul, Korea \\ ${ }^{2}$ Department of Emergency Medicine, Konkuk University Chungju Hospital, Konkuk University School of \\ Medicine, Chungju, Korea
}

Carbon dioxide is widely used for a variety of purposes. As it is a normal constituent of air, the public generally regards it as safe. Although low concentrations of carbon dioxide are not harmful to human beings, high concentrations are toxic, and can cause serious harm, including cardiac arrest. Only a limited number of cases of carbon dioxide intoxication have been reported in Korea, and they have all been mild, with no cases of cardiac arrest following acute exposure to high concentrations of carbon dioxide, reported previously. We describe a case of carbon dioxide poisoning following an explosion of a carbon dioxide tank, which led to cardiac arrest in a 66-yearold patient. This cardiac arrest could have been avoided if the patient was fully aware of the hazardous effects and serious consequences of exposure to high concentrations of carbon dioxide.

Keywords Carbon dioxide; Poisoning; Heart arrest; Occupational health

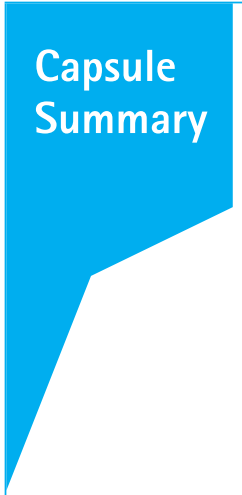

What is already known

Carbon dioxide is used widely nowadays for various reasons. However, the general public commonly overlooks its potentially dangerous features when accumulated in a confined space. There have been few reports of cardiac arrest due to carbon dioxide poisoning in the western society.

\section{What is new in the current study}

Some reports about carbon dioxide intoxication have been made in Korea, but they were all about minor cases of intoxication that cause almost no harm to the victims. We report a case of carbon dioxide poisoning, which happened in Korea, that led to cardiac arrest.
eISSN: 2383-4625

Received: 20 February 2019

Revised: 29 March 2019

Accepted: 3 April 2019

Correspondence to: Jin Yong Kim Department of Emergency Medicine, Konkuk University Chungju Hospital, Konkuk University School of Medicine, 82 Gugwon-daero, Chungju 27376, Korea

E-mail: palenova@kku.ac.kr ORCID

https://orcid.org/0000-0002-1406-9848

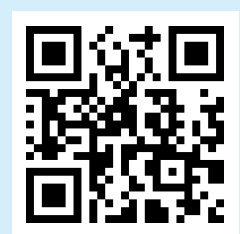

How to cite this article:

Ok YB, Kim JY, Baek KJ, Lee KR, Hong DY, Park SO, Kim JW, Kim SY. Case of cardiac arrest due to carbon dioxide poisoning following an explosion of a carbon dioxide tank. Clin Exp Emerg Med 2020;7(3):234237. https://doi.org/10.15441/ceem.19.015

This is an Open Access article distributed under the terms of the Creative Commons Attribution Non-Commercial License (http:// creativecommons.org/licenses/by-nc/4.0/). 


\section{INTRODUCTION}

Carbon dioxide, the fourth most common gas in the atmosphere, is widely produced and utilized by many industries for purposes such as refrigeration, fire suppression, and as a solvent. ${ }^{1}$ Carbon dioxide has a molecular weight that is heavier than that of oxygen, and so it may accumulate if it is released in enclosed environments. A possible result of carbon dioxide accumulation is what is known as confined space hypoxic syndrome, in which the atmospheric deficit of oxygen can cause life-threatening conditions. At low concentrations, carbon dioxide exposure does not cause any symptoms. However, exposure to high concentrations of carbon dioxide can have serious consequences. ${ }^{2}$ The National Institute for Occupational Safety and Health recommends that short-term occupational exposure should not exceed 30,000 ppm over a period of fifteen minutes. ${ }^{3}$ Air containing 40,000 ppm of carbon dioxide poses an immediate threat to human life and health. Victims of carbon dioxide exposure may experience a wide range of symptoms. These symptoms can range from mild, such as headache, dizziness, and drowsiness, to severe, such as loss of consciousness, visual disturbances, and hearing difficulties. ${ }^{4}$ At higher concentrations, carbon dioxide can cause an instantaneous loss of consciousness and respiratory arrest because it acts both as an asphyxiant, and a toxicant. ${ }^{2}$ In Western societies, there have been case reports of carbon dioxide intoxication that has led to cardiac arrest. However, only a limited number of cases of carbon dioxide poisoning have been reported in Korea, and all these reports have been of mild intoxication. Here we describe a case of carbon dioxide poisoning following an explosion of a carbon dioxide tank, which led to cardiac arrest. This cardiac arrest could have been avoided if the patient had been fully aware of the hazardous effects and serious consequences of exposure to high concentrations of carbon dioxide.

\section{CASE REPORT}

A 66-year-old male with a history of hypertension arrived at the emergency department with cardiac arrest. On arrival, he was comatose and electrocardiography confirmed that his heart had stopped. Thus, cardiopulmonary resuscitation (CPR) was continued. The emergency medical service providers accompanying the patient reported that they had been dispatched to the scene after receiving a call about an explosion in a building. When they arrived at the site, they discovered two unconscious people lying on the floor. One of the two was our patient. With the patient not having received any bystander CPR, the emergency medical service providers promptly initiated CPR, and inserted a laryngeal mask airway before transporting him to our emergency medical center. It took about 20 minutes to get to the hospital.

The patient's initial arterial blood gas analysis showed the following results: pH 6.63, partial pressure of carbon dioxide 201.6 $\mathrm{mmHg}$, partial pressure of oxygen $8.9 \mathrm{mmHg}$, capillary oxygen saturation 3.0\%, and bicarbonate $20.6 \mathrm{mmol} / \mathrm{L}$. After receiving six minutes of CPR at the emergency department, the patient had a return of spontaneous circulation. Electrocardiography directly after the return of spontaneous circulation showed atrial fibrillation, but no remarkable ST segment changes. The results of bedside Focused Abdominal Sonography for Trauma, and transthoracic echocardiography, were normal. Portable chest radiograph showed no active lung lesions. His non-enhanced brain computed tomography showed no evidence of acute intracranial hemorrhage. After starting a mechanical ventilation, serial arterial blood gas analysis findings improved rapidly. Carbon dioxide concentration decreased rapidly, and it returned to normal within half an hour (Table 1).

Later, police officers visited the emergency room to check the patient's condition. They showed a closed-circuit video of the explosion, and informed the medical staff about what had happened in more detail. A closed-circuit camera was not installed in the room where the explosion had occurred, but a camera was located in the passageway directly outside the room. They did not have information on the dimensions of the room, or the characteristics of the tank that had exploded but specified that the tank contained carbon dioxide. On being informed of the explosion, two supervisors approached the room in which the explosion had occurred, without wearing any protective equipment, but they did not enter it. Within a few seconds, they became unconscious and collapsed to the ground without any warning.

Even though the patient recovered spontaneous circulation

Table 1. Results of serial blood gas analysis

\begin{tabular}{lcccc}
\hline ABGA & $\begin{array}{c}\text { During } \\
\text { CPR }\end{array}$ & $\begin{array}{c}10 \text { min after } \\
\text { ROSC }\end{array}$ & $\begin{array}{c}30 \text { min after } \\
\text { ROSC }\end{array}$ & $\begin{array}{c}2 \text { hr after } \\
\text { ROSC }\end{array}$ \\
\hline $\mathrm{pH}$ & 6.627 & 6.902 & 7.172 & 7.238 \\
$\mathrm{pCO}_{2}(\mathrm{mmHg})$ & 201.6 & 124.2 & 25.7 & 44.3 \\
$\mathrm{pO}_{2}(\mathrm{mmHg})$ & 8.9 & 281.1 & 249.3 & 103.1 \\
$\mathrm{HCO}_{3}(\mathrm{mmol} / \mathrm{L})$ & 20.6 & 12 & 9.2 & 18.5 \\
$\mathrm{sO}_{2}(\%)$ & 3 & 98 & 99.2 & 96.5 \\
$\mathrm{O}_{2} \mathrm{Hb}(\%)$ & 2.9 & 92.4 & 94.5 & 93.5 \\
$\mathrm{COHb}(\%)$ & 2 & 5.9 & 4.5 & 3 \\
$\mathrm{MetHb}(\%)$ & 1.7 & 0.2 & 0.2 & 0.1 \\
\hline
\end{tabular}

$\mathrm{ABGA}$, arterial blood gas analysis; CPR, cardiopulmonary resuscitation; ROSC, return of spontaneous circulation; $\mathrm{pCO}_{2}$, partial pressure of carbon dioxide; $\mathrm{pO}_{2}$ partial pressure of oxygen; $\mathrm{HCO}_{3}$, bicarbonate; $\mathrm{sO}_{2}$, oxygen saturation; $\mathrm{O}_{2} \mathrm{Hb}$, oxyhemoglobin; $\mathrm{COHb}$, carboxyhemoglobin; MetHb, methemoglobin. 
within 26 minutes, he failed to restore his mental function in the emergency department, and started showing jerking movements, which raised the possibility of a seizure from carbon dioxide toxicity or hypoxic brain damage. After consulting with a neurologist, the patient underwent a portable electroencephalogram (EEG), which showed generalized epilepsy (Fig. 1A). He was admitted to the intensive care unit (ICU) under the care of the pulmonology department. EEG and diffusion magnetic resonance imaging were recommended after neurology department consultation a few days after ICU admission. A portable EEG, done three days after the patient's ICU admission, showed severe diffuse cerebral dysfunction (Fig. 1B). Diffusion magnetic resonance imag- ing, performed two days later, showed that he had hypoxic brain damage (Fig. 2). A chest radiograph, taken the same day revealed increased haziness in the left lower lung field, indicating the presence of pneumonia (Fig. 3). C-reactive protein levels, measured daily for patient monitoring, gradually increased. After starting antibiotics, C-reactive protein level soon decreased to within the normal range. A follow-up EEG, done 6 days after his admission showed no significant interval change (Fig. 1B). As the patient's mental function had not improved, his family requested that he be transferred to another hospital for supportive care. The patient was transferred to a neighboring hospital on the seventh day of his hospitalization.
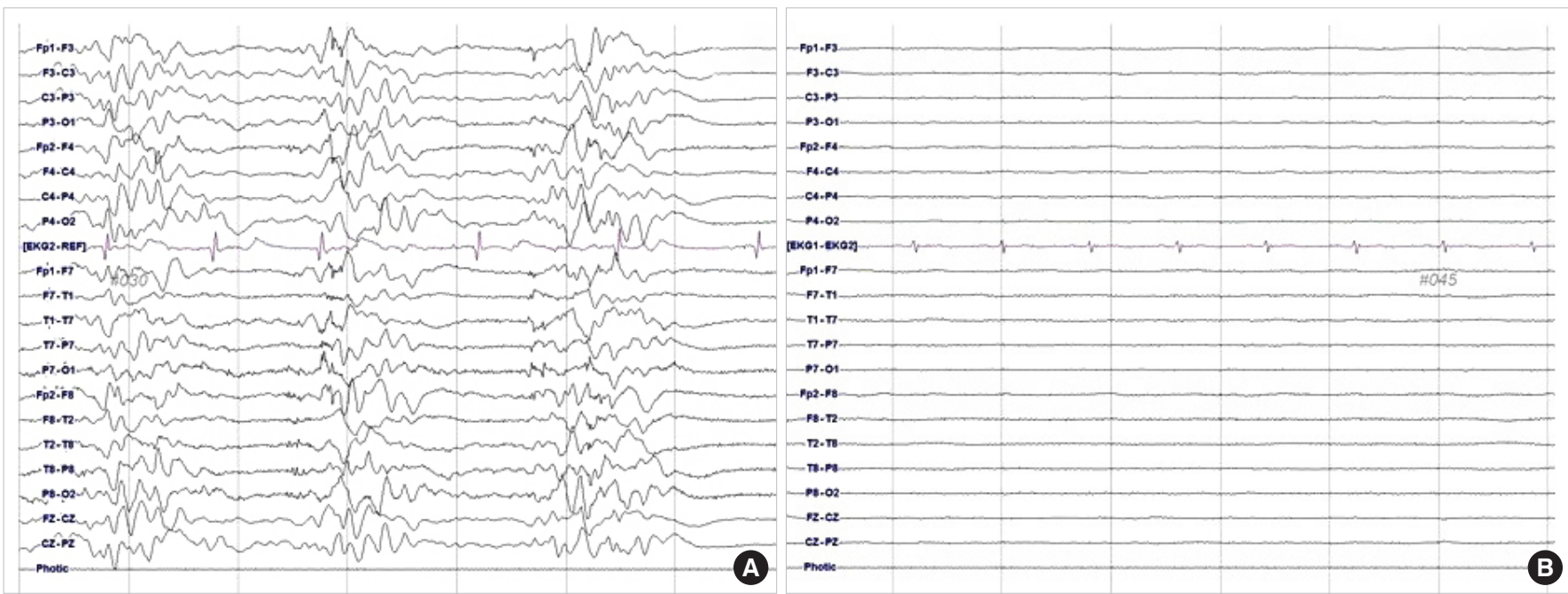

Fig. 1. Portable electroencephalogram findings of the patient (A) at the emergency department showing generalized epilepsy and (B) at 3 days of admission.

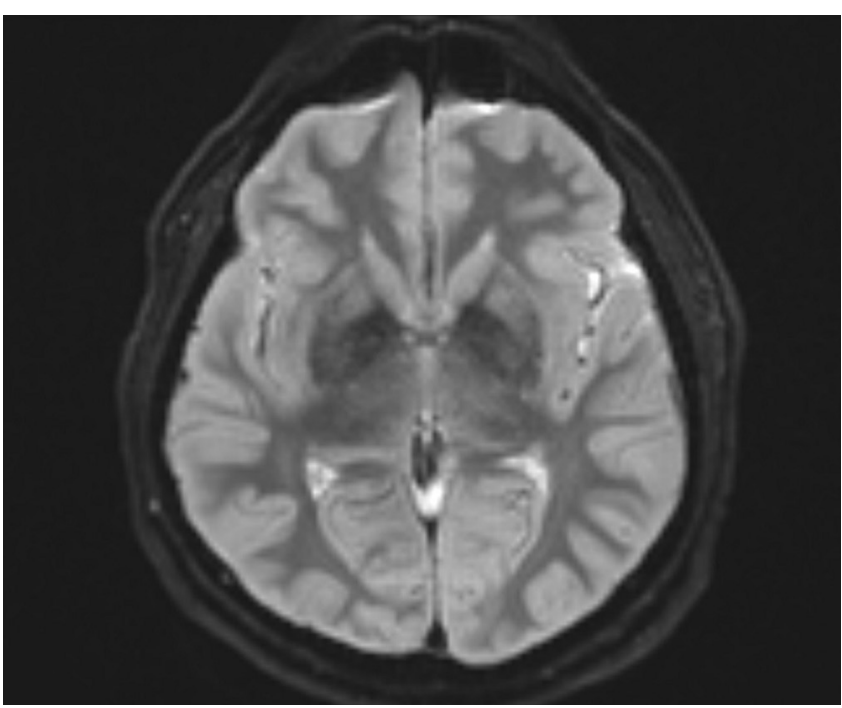

Fig. 2. Diffusion magnetic resonance imaging finding of the patient at 5 days of admission showing hypoxic brain damage.

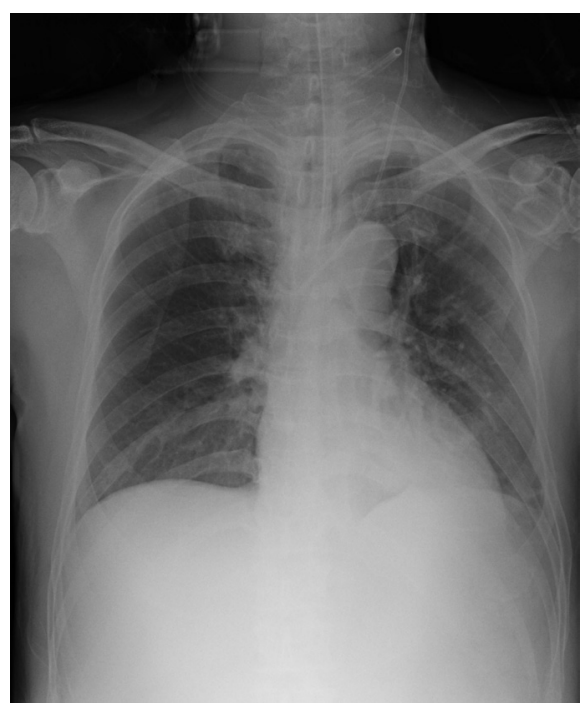

Fig. 3. Chest radiograph of the patient showing haziness in the left lower lung field after 5 days of admission. 


\section{DISCUSSION}

The dangers of carbon dioxide due to its daily industrial utilization, are not widely recognized and are easily overlooked. ${ }^{1}$ However, since the early 1900s, there have been intermittent reports of accidental or intentional carbon dioxide poisoning. In 1958, Williams ${ }^{5}$ described an incident of accidental carbon dioxide poisoning caused by onions in a cargo ship. There were eight casualties, including two fatalities. In 2009, Dunfor et al. ${ }^{3}$ reported a fatal case of carbon dioxide poisoning caused by dry ice that was being used for cooling while a refrigerator was being repaired. In 2005, Hsieh et al. ${ }^{6}$ reported a case of a 33-year-old worker in a public relations company in Taiwan being poisoned by carbon dioxide from dry ice used for special effects in an election campaign. In 2013, Rupp et al. ${ }^{4}$ reported two cases of suicide in which carbon dioxide was used in Germany. Contrary to these reports of critical and fatal cases of carbon dioxide poisoning in other countries, the few cases of carbon dioxide poisoning that have been reported in Korea have all been mild.

The famous 1986 Lake Nyos disaster of Cameroon, which killed thousands of people and livestock, has been attributed to a massive release of carbon dioxide from a volcanic eruption. ' With the exception of the Lake Nyos disaster, naturally-occurring carbon dioxide in open spaces is generally not a problem because it diffuses into the air, and the concentration remains too low to be harmful to humans. On the other hand, carbon dioxide will replace oxygen in confined spaces, such as freezers, fermentation vats, mines, rooms, and basements, because it is heavier than oxygen. This may lead to intoxications with critical consequences such as asphyxiation and arrest. All the case reports mentioned above, and the case reported in this article, occurred in confined spaces where carbon dioxide had nowhere to spread. Our case is unique in view of the rarity of cardiac arrest caused by highlyconcentrated carbon dioxide exposures in a confined space over a short period.

Had he been knowledgeable about the risk of carbon dioxide accumulation and the means to prevent carbon dioxide poisoning, our patient could have taken evasive action when the tank exploded. Even though being in charge of the tanks posed a hazard, he seemed ignorant of safety precautions. This ignorance is probably not limited to this case. In Korea, the potential hazards of carbon dioxide exposure are generally underestimated due to the paucity of reports of serious exposure-related incidents. Nam et al. ${ }^{8}$ described a case of a 19 -year-old patient presenting to emergency department with accidental carbon dioxide poisoning caused by dry ice. Jeong et al. ${ }^{9}$ reported a mass casualty incident caused by malfunctioning of a carbon dioxide-based fire extinguishing system. However, these two reports, were about mild intoxication from which the individuals affected recovered fully within a few hours. There is the potential for future incidents of critical carbon dioxide poisoning similar to the case described in this article. Moreover, studies in the USA during the 1980s showed that $22 \%$ of cases of carbon dioxide poisoning occurred during rescue efforts. This figure has remained relatively unchanged. ${ }^{2}$

In conclusion, primary responders and the general public need to be educated regarding the dangers of carbon dioxide accumulation in confined spaces and the need to evacuate the space, unless wearing proper equipment, if an incident occurs.

\section{CONFLICT OF INTEREST}

No potential conflict of interest relevant to this article was reported.

\section{REFERENCES}

1. Scott JL, Kraemer DG, Keller RJ. Occupational hazards of carbon dioxide exposure. J Chem Health Saf 2009;16:18-22.

2. Permentier K, Vercammen $S$, Soetaert $S$, Schellemans C. Carbon dioxide poisoning: a literature review of an often forgotten cause of intoxication in the emergency department. Int $J$ Emerg Med 2017;10:14.

3. Dunford JV, Lucas J, Vent N, Clark RF, Cantrell FL. Asphyxiation due to dry ice in a walk-in freezer. J Emerg Med 2009;36:353-6.

4. Rupp WR, Thierauf A, Nadjem H, Vogt S. Suicide by carbon dioxide. Forensic Sci Int 2013;231:e30-2.

5. Williams HI. Carbon dioxide poisoning: report of eight cases, with two deaths. Br Med J 1958;2:1012-4.

6. Hsieh CC, Shih CL, Fang CC, Chen WJ, Lee CC. Carbon dioxide asphyxiation caused by special-effect dry ice in an election campaign. Am J Emerg Med 2005;23:567-8.

7. Baxter PJ, Kapila M, Mfonfu D. Lake Nyos disaster, Cameroon, 1986: the medical effects of large scale emission of carbon dioxide? BMJ 1989;298:1437-41.

8. Nam SS, Kwak KH, Lee SB, Do BS. A case of carbon dioxide poisoning from dry ice inhalation. J Korean Soc Emerg Med 2011;22:295-8.

9. Jeong WJ, So BH, Kim HM. A case of carbon dioxide poisoning by malfunction of a carbon dioxide-based fire extinguishing system. J Korean Soc Emerg Med 2012;23:295-7. 